\title{
El Seminario y otros cuentos
}

\author{
Luis Diego Soto Delgado ${ }^{1}$
}

\section{EI Seminario}

-¡Te amo! - me dijo él, una tarde de verano, caliente, pero ventosa. La compañía era perfecta, el hombre que me amaba era lo mejor que podía tener. 1

Hace dos años de haber ingresado al Seminario. Quería ser sacerdote, siempre lo supe, pero no lo hice por falta de decisión. Tenía veinte años cuando inicié mi proceso vocacional: entrevistas, charlas, hablar con mis padres.

Recuerdo la primera entrevista. Fui tan sincero como pude, dije la verdad: así como Jesús lo hizo antes de morir. Estaba nervioso, porque nunca había hablado con nadie de lo que advertían mis entrañas. Jamás había amado: era virgen. Me descubrí ante un sacerdote. Sentí miedo, pero lo afronté.

Por haber sido sincero, fui aceptado. Cuando me dieron la noticia fui el joven más feliz sobre la tierra.

1 La revista Repertorio Americano externa una disculpa, pues en la edición del N. 24 (2014), estos cuentos fueron atribuidos a otro autor, por un error nuestro. Hoy, nos retractamos y damos el crédito al verdadero autor.
El sacerdote que aceptó mi ingreso me explicó por qué fui admitido: "tu naturaleza es seducida por los de tu misma carne, fuiste muy sincero, pero la balanza se inclinó a tu lado al confesar que no has caído en el pecado de la lujuria" Esas palabras aún retumban en mi mente.

La primera clase del seminario fue inolvidable para mí. Ahí lo conocí y mis pensamientos sufrieron una alteración. Él entró a la clase con una mirada que a mi parecer fue... única. Tomó asiento a mi lado.

- Mucho gusto - escuché decir. Me tendía la mano. Siguió diciendo:

-Mi nombre es Carlos. Y vos ¿Cómo te llamás?

Esas palabras fueron la semilla de nuestra historia. Con el paso del tiempo, nuestra conexión se hizo más cercana. Compartíamos cada momento del día: la hora del almuerzo, las clases, en los jardines. Mis sentimientos se agitaron, mi mente se obnubiló: fueron sus besos, caricias, detalles, los que colaboraron a forjar en mí el sentimiento del amor. Jamás me había enamorado, jamás nadie me había besado y fue en el seminario donde sentí el placer que 
provocaba el amor. Lo único que no compartíamos era la habitación. Yo lo deseaba, pero no fue hasta una noche lluviosa cuando escuché que tocaban a mi puerta. Era él, con su pijama y su mirada indefinida. La excitación que me provocaba un ser humano desnudo, el contacto físico, fue algo tan maravilloso que aún siento su respiración en mi cuello, la huella de sus labios aún me dan escalofríos.

¿Por cuál razón estaba él enamorado de mí? Se lo pregunté muchas veces. Su respuesta no me llevaba al cielo, me transportaba al límite del universo, me llevaba a lugares donde la comprensión humana era estúpida e irracional.

Er era muy inteligente, el primero en todos nuestros cursos, sin embargo su inteligencia fue un arma de doble filo. $\mathrm{Su}$ ironía y arrogancia para con los demás, las aplicó conmigo.

Todo comenzó en el curso de Historia del Cristianismo. El historiador relataba hechos sobre las relaciones antinaturales que los paganos practicaban y que el cristianismo y la Iglesia Católica reprendían. El "Diccionario Infernal" calificaba a Kelen y Nisroch como promotores de dichas relaciones ilícitas. ¡Los odio tanto! ¡Ese maldito me arrebató a Carlos! Así como los días de gloria llegaron, se fueron. Fue como el alba: hermosa pero corta. Duró tan solo un año y un puñado de meses.

Los besos, las caricias y los orgasmos se habían convertido en tormentos, lágrimas y desplantes. Cada desprecio era como ser lanzado a un vacío donde Dios no existía. Carlos se alejó de mí poco a poco: me evitaba, asiento lejos de mí en los cursos... Fue mi primer desamor.

Estas líneas son un legado: de lo que lloré, de lo que sufrí por ilusionarme por algo que creí verdadero, pero que no era verídico. Abandoné el seminario. No podía seguir viéndolo, en cada clase, en cada pasillo y soportar sus malos tratos. Aparentemente, su inteligencia solo era memoria, pero no raciocinio.

La tarde que me fui era caliente y ventosa. Tal y como cuando nos encontrábamos y él me decía "te amo" incontables veces. Mi mano sostenía mi pequeña valija y el viento acariciaba mi rostro.

\section{Cuando hice magia negra}

El viento azota las paredes de mi morada. La noche me envuelve en tribulaciones y el abandono de marido se une a mí.

Las noches: mis amigas inseparables. Ellas son testigos de lo que recorre mi rostro, esa diminuta huella de humedad. Esta humedad es la prueba de lo que sufro por alguien que ni siquiera nota mi existencia, que solo me usa para esconder su sodomía hipócrita y para dárselas de gran hombre, amante de mujeres que solo buscan orgasmo.

Placer pasajero es lo que una promiscua gratuita anda en busca; y mi marido ofrece sus servicios de saciedad orgásmica a cambio de nada. Eso me lleva al país de la indignación, un lugar donde la barbarie no tiene límites, donde el concepto del rencor, odio y descaro son suplidos por los del amor, sinceridad y paz. Pero mi marido 
es tan dadivoso que sacia a hombres y a mujeres por igual.

Esta noche de soledad se suma a las innumerables veces en las que duermo sola. El pasado de mi niñez se arrincona en mi consciente. Los demonios surgen en mí como maleza en jardines, como cáncer en mis pulmones producto del fumado desde niña, como el odio y repudio al sentirme burlada por un hombre que solo me utiliza y no ve lo que hay en mí, lo que siento por él y lo que puedo hacer con tal de tenerlo a mi lado.

Los recuerdos caen como gotas de lluvia: una tras otra humedecen la superficie terrestre. Estas memorias son más valiosas que el oro. Ahora la duda no me da tranquilidad, ahora la duda me alienta a descubrir la verdad y darme ánimos para detener las burlas de mi abandono marital.

Recuerdo mi niñez. Vivida entre crianza de hermanos y pobreza extrema. Vivencias de burlas por otros, por no tener una figura paterna que estuviera al lado de mi madre. Los días que cuidaba a mis hermanos hacía comida, cambiaba pañales; soportaba los gritos de mi madre al reprenderme por no hacer los deberes de la casa como toda una mujer. Mi mamá pretendía que hiciera deberes de mujer adulta a tan solo mis doce años. Así viví mi infancia, siendo una madre de crianza a temprana edad, aún siendo una niña, jugando con muñecas reales: mis hermanos.

En las vacaciones escolares mi madre también tenía esos días libres. Pero no hacíamos viajes donde familiares ni tenía descanso. Más bien, tenía más labores por hacer, más labores domésticas.
Recuerdo una tarde de verano. La suave brisa, fresca y continua, apaciguaba el calor y el sol iba ocultándose lentamente por el oeste. Mis hermanos, mi madre y yo estábamos limpiando el patio trasero de una casa prestada. Mi madre utilizaba un rastrillo para apuñar la maleza del pequeño patio, mis hermanos apilaban los montículos de hierba en uno solo, para luego quemarlo. Llevábamos mucho tiempo removiendo puñados de maleza cuando mis hermanos y yo encontramos algo inusual al terminar de remover un montículo. Encontramos una pequeña trampilla de roca, un tipo de lápida colocada horizontalmente sobre el suelo. En el centro, había una leyenda que rezaba: "Anneliese la Valiente”. Anneliese... esa palabra, ¿Qué

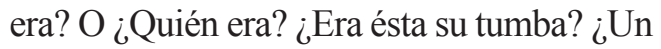
tributo de alguna hazaña heroica? Esas preguntas aún rondan en mi cabeza, aún las recuerdo como si las hubiera visto hace unos instantes. Mi hermano Iván y yo nos vimos mutuamente. Fue ahí cuando supe que era curiosa, que me gustaba descubrir el porqué y el cómo de las cosas. Me sentí atraída hacia lo que habíamos encontrado, quería saber por qué un objeto como ese se hallaba en un lugar tan remoto.

Sin más preámbulos, me dirigí a elevar la losa. Mi hermano me ayudó a hacerlo. No era muy pesada, puesto que era delgada para la apariencia que tenía. Aparentaba ser pesada, gruesa pero fue lo contario. Al retirarla de su lugar, apreciamos deslumbrados lo que cubría la losa: un pequeño agujero de forma circular, de no más de cuatro pulgadas de diámetro. Pero mi curiosidad e intuición me advertían que había algo más en ese agujero. No dudé en introducir mi mano en nuestro hallazgo para saciar mi curiosidad. 
Gracias a esa tarde me di cuenta de que soy intrépida, atrevida, decidida y no le temo a los retos ¡Oh verano más dichoso! Esta noche es decisiva, no temeré poner en práctica lo descubierto en mi infancia, en aquella tarde, en aquel agujero, en aquel libro que saqué del hoyo y que mi madre, luego de leerlo en voz alta, lo quemó por completo. El contenido del libro aún vive en mi mente, es lo que me ayudará a saber la verdad. La verdad que quiero saber y mi marido me oculta. Pondré en práctica ese contenido del libro que seguramente pertenecía a Anneliese y me ayudará a no permitirle a mi esposo una burla más. Sus orgasmos gratuitos serán confesados por su boca, esa misma que usa para besarme y besar a otros y otras. Esta noche se acaba todo, en esta noche se sabrá todo y lo que más me emociona, es que él mismo será el que confiese todo. Sus propias palabras lo delatarán y no habrá duda alguna de sus mentiras.

Escuché abrirse de golpe la apertura. Las horas habían pasado como segundos. Los viajes a recuerdos pasados colaboran a que el tiempo no nos juegue un mal rato. Sosteniéndose sobre sí mismo, pero a punto de caer al suelo, llegó mi marido. El licor era su colonia favorita. Al cabo de unos instantes, luego de quitarse los zapatos, se acostó a mi lado. No demoró en estar dormido. Ahora es cuando mi trabajo comienza pero, antes de ponerme en labores investigativas, debo ver con quién estuvo esta noche. Así que introduje, sigilosamente, mi mano en su bolsa del pantalón y encontré la primera señal de su descaro diario: un preservativo usado. Húmedo y con contenido líquido en su interior. Pero esto no me indica nada. El olor a perfume que su amante deja en su cuello es la pista y el de esta noche no es de mujer... no hay rastros de pintura labial ni olores dulces en su ropa y cuello. La respuesta es evidente para mí, no necesito indagar más.

Recuerdo las instrucciones del libro. Mi madre lo destruyó, pero aún existe en mi mente, así que me propuse seguir las instrucciones. Me coloqué sobre mis pies y me dirigí a la cocina, una vez ahí tomé un cuchillo y me dispuse a afilarlo. El patio trasero era el escenario donde haría los preparativos para descubrir la verdad. Sin lugar a dudas, a mis hijos no les molestaría prestarme a su pequeña mascota. Bastó un pequeño viaje de la hoja del cuchillo alrededor del cuello de Lobo.

Corazón e hígado era lo único requerido del cadáver del perro. Lo demás, ya no era útil. Su corazón aún palpitaba levemente, debía apresurarme si quería descubrir la verdad. Una vez en mi habitación, me coloqué delante de la cama donde mi esposo yacía ebrio. Cerré mis ojos y mis recuerdos fueron los que actuaron ahora: recordaba palabra por palabra la oración dicha por mi madre.

Uno, dos, tres, cuatro, cinco, seis...

De los que tienen diferentes nombres,

Vengan aquí.

Uno, dos, tres, cuatro, cinco, seis...

De los que son opuestos, de los que son temidos y odiados,

vengan aquí

Yo, los llamo. Yo, los invoco. Yo, les pido que me complazcan.

Complazcan a esta humilde sierva que pide el favor a ustedes.

Uno, dos, tres, cuatro, cinco, seis... 
Lentamente pronuncié esas palabras. Abrí los ojos y me dispuse a removerle la camisa. Sobre su pecho, coloqué el hígado y el corazón del animal, las palpitaciones del corazón eran apenas sensibles, pero latía. Luego, lentamente cerré mis ojos y pronuncié las siguientes palabras:

Mentiras ocultas en la mente de este hombre hay.

Quiero saberlas.

Quiero que me las diga.

Quiero la verdad dicha por boca de este hombre presente.

La temperatura en el ambiente disminuyó de golpe. Ahora, el frío, la obscuridad de la habitación y mi método para saber la verdad eran mis compañeros. En mi mente visualizaba lo que quería saber. No era un deseo, ni un anhelo, era un propósito. Algo que estaba decidida a llevar a cabo, sin interrupciones ni fallos. Estaba cansada de burlas y de ser la segunda en todo sentido, no me casé para esto y si esto es lo que estoy viviendo, lo voy a cambiar. Merezco ser feliz, ser próspera y estar en paz conmigo misma.

Mi concentración era poderosa. Mi mente era como un trozo de papel blanco con un punto negro en el centro: el papel blanco era mi mente y el punto negro era mi objetivo. En la meditación, sentí el leve rocío de una brisa. Tan helado como el hielo, tan espontáneo como un parpadeo. Pero eso no fue lo único que sentí en la habitación. Había una presencia a mi lado izquierdo, escuchaba la respiración de ese espíritu invocado por mí, que acudía a mi llamado.
Escuché una lengua extraña y desconocida. La escuchaba en mi mente, recorría mis venas. Sonidos siseantes y prolongados eran los de aquella lengua extraña. Sabía que eran los seis de la letanía. Eran ellos. Habían venido, atendieron mi llamado.

-"Pregúntale"- escuché en mi mente. Esa palabra fue prolongada. Ellos me daban instrucciones.

Abrí mis ojos y no temí ante lo que apreciaba. El corazón del perro estaba adherido al pecho de mi esposo y latía como si estuviera dentro del cuerpo del animal, la sangre se derramaba por las válvulas cortadas por el cuchillo. Sus palpitaciones eran rápidas y cortas. El cuerpo de mi marido estaba rígido y pálido, sus ojos estaban abiertos y blancos. Su estado sugería que no estaba consciente de sí, ni siquiera estaba ebrio.

Ahí me quedé. A su lado, de cuclillas y mirándolo directamente a los ojos. Ahora mi interrogatorio daría inicio, ahora todas sus faltas las dirá sin mentiras. Ahora yo soy la del control, ahora él es el oprimido y yo soy la opresora. Yo soy la que tiene el poder.

-Tu nombre - le ordené. Mi mirada era fija $\mathrm{y} \sin$ titubeos.

-Manuel - respondió mi esposo. Solo quería la verdad y estoy a punto de hacerme dueña de esta.

-¿Con quién estuviste esta noche? - pregunté con voz suave, pero a la vez firme y directa.

-Con Iván - respondió él. 
- ¿Mi hermano?

-¡Sí! - respondió Manuel.

¡Otra vez me sentí burlada! Es mi hermano menor uno de los amantes de mi esposo. Pero proseguí.

-Dime el nombre de todos tus amantes ordené nuevamente. Entre los nombres que pude reconocer, estaban los de unas cuantas vecinas, primas y otros que no tenía la más remota idea de quiénes eran.

-¡Cállate! - dije en un grito ahogado. Él se detuvo. No podía seguir escuchando tanto descaro. Pero eso era lo que quería: saber la verdad, para dejar de ser famosa en un mundo del cual no sabía que formaba parte. Seguí haciendo preguntas y recibiendo respuestas verdaderas pero crueles.

El destino de mi marido Manuel tenía rumbo fijo: dormir eternamente. El caer en un sueño sería su cura y la mía.

-Irás a la cocina, tomarás un cuchillo y harás una profunda incisión en tu cuello. Ahí mismo quedarás.

Él se levantó de la cama y se dirigió a la cocina. Mientras tanto, yo me acosté. Reposé mi cabeza sobre la almohada y me relajé. Al cabo de unos instantes escuché un fuerte grito. Supuse que su sangre desfilaba por su cuerpo, debió ser glamoroso ver las formas como la sangre fue decorándolo. De esta forma me libraba de toda culpa y responsabilidad. Cuando la policía investigue la muerte de Manuel, sospecharán que yo fui su asesina, la sorpresa será al descubrir que mi esposo fue el que se quitó la vida. Él solo terminó su existencia mediocre y promiscua. Lo que las autoridades nunca llegarán a saber, es que fui yo la promotora de dicho hecho macabro.

Mis hijos llorarán, pero el tiempo hará su trabajo. Esa noche, fue la última en la que él cometió pecado y yo hice magia negra.

\section{Las trece palabras}

Nadie tiene las palabras para desafiar las leyes de la física. Nadie de este mundo tiene en su poder las palabras para hacer lo que se le antoje. Y eso Lázaro lo tenía muy presente.

A inicios del siglo $\mathrm{XX}$, los campesinos adinerados se sentían afortunados o bendecidos por Dios, por haberles dado tanta riqueza. Eran los prejuicios que los hacendados y sacerdotes enseñaban a los más incrédulos. Así recordaba el mundo donde creció, donde las hijas de los hacendados lo tomaban como pasatiempo sexual, dados sus dieciséis años. Con tal de llevarlo a la cama, le hacían propuestas que jamás cumplieron. Y amenazaban al pobre de acusarlo de robar dineros de la habitación de los padres de las muchachas, si no saciaba sus deseos. Las Señoritas estaban sedientas de placer y lo obtenían. Eso recordaba Lázaro, en su lecho de muerte. Rodeado por todo ese lujo y riqueza, que en el pasado habían gozado los hacendados.

Sus ciento dos años le pesaban sobre su frágil cuerpo. La respiración del Lázaro viejo era pesada y lenta. Sentía que cada minuto de su vida era una agonía.

Su hija mayor entró en la lujosa habitación, decorada con cortinas de seda y muebles de 
la más fina estirpe, elaborados por artesanos de otras naciones, traídos por capricho del mismo Lázaro. Isabel caminaba sigilosamente hacia la cama de su padre, seguida del médico que lo había estado asistiendo por los últimos veinticinco años. El médico se situó al lado izquierdo de Lázaro.

-¡Aléjate de aquí!- musitó con un hilo de voz.

-¡Él viene a ayudarte, papá!- lo reprendió suavemente Isabel.

Lázaro miró al médico por un instante.

¡El lado izquierdo es de él! - terminó añadiendo Bernal.

El médico e Isabel se miraron por un instante. No era la primera vez que Lázaro ordenaba a una persona quitarse de su lado izquierdo, aludiendo que ése era el lugar de "Él".

-Nadie debe permanecer a mi izquierdaañadió el viejo.

El doctor examinó sus signos vitales. Su pulso era lento y su temperatura superaba los cuarenta grados.

¿¿Ha estado tomando los medicamentos?-

-¡Claro que sí, Doctor!- aseguró Isabel con tono serio y voz baja- Los tengo bajo supervisión estricta a ambos: a él y a su enfermera.

-Entonces, no comprendo por qué empeora. Lázaro ha sufrido varios paros cardiacos, se ha enfermado varias veces de cólera, se ha intoxicado siete veces...- resumió con asombro-. Y todo esto, durante los últimos veinticinco años. La verdad, estoy desconcertado, Señorita Isabel.

- ¿Puede imaginar cómo nos encontramos nosotros? Mi padre parece enfermarse de nuevo. Cada día está más delgado, débil y pálido- concluyó Isabel mirando a su padre, quien prestaba mucha atención a lo que decían.

-Mi consejo es que sigan con el cuidado que ha recibido hasta el día de hoy. Además, le brindaré medicinas diferentes, para ver cómo reacciona.

El médico sacó dos frasquitos Uno contenía un jarabe; el otro, unas pastillas diminutas. Tomó un trozo de papel y escribió las dosis en que debían ser suministradas a Lázaro.

Isabel tomó los frasquitos y la nota y los colocó en la mesita de noche, al costado derecho de la cama de su padre.

-¡Muchas gracias por venir, Señor Cristóbal!agradeció Isabel al médico- El mayordomo cancelará sus servicios y las medicinas.

-Isabel... necesito hablar contigo un momento- le dijo Lázaro.

Ella asintió con un leve movimiento de su cabeza. Cerró la puerta de la habitación.

-Ponle llave a la puerta. No quiero que nadie nos interrumpa- indicó Lázaro. Isabel se sentó sobre el lado derecho de la cama.

-Mi hora ha llegado. Hace muchos años debí morir...pero hay algo que me lo impide. No podré hacerlo hasta que yo mismo destruya esta enorme muralla que me separa de la muerte 
-¡Pero Papá!- exclamó su hija-¿De qué hablas?

-Él vendrá esta noche... así como lo ha hecho los últimos treinta años. Ya no quiero que venga.

-¿Quién? ¿Quién no quieres que venga? ¿El médico? Él movió la cabeza negando. Continuó:

-Fue hace más de ochenta años. - dijo Lázaro, con la mirada fija y llena de temor Él me dijo que podía tener lo que quisiera.

-Papá...dime lo que quieras. Yo no te culparé de nada - lo animó ella, con una voz suave y tenue.

Continuó hablando, sin que ella hubiese dicho nada.

-Él me dio trece palabras...para obtener lo que quisiese: la mujer más bella, la casa más grande y lujosa, las mejores cosechas, destruir a mis enemigos, alejar las sequias y los vientos huracanados que pudieran destruir mis cosechas.

-¿Quién te dijo esas palabas?- preguntó Isabel con prisa.

Lázaro abrió su boca, pero no logró decir nada, sentía vergüenza. Vergüenza de haber conseguido toda su riqueza a base de palabras, palabras que a nadie le dijo, palabras vacías y embusteras.

-Él...-dijo Lázaro - viene cada noche a burlarse de mí. La felicidad le invade cuando me visita cada noche.
-¿Quién te visita? Nadie entra en tu habitación. ¡La enfermera vigila la entrada todas las noches! - afirmaba Isabel.

-Ella dice que estoy loco, ¿cierto? pero no lo estoy. Lo que ella escucha son las conversaciones que tengo con Él. Hija mía... ¿Quieres que descanse en paz?

-¿Qué debo hacer para que eso suceda?murmuró Isabel, ansiosa por saber.

-Acércate - le dijo Lázaro. Susurró trece palabras al oído de su hija. Al principio Isabel pensó que su padre tenía problemas mentales por los disparates que le susurraba.

- No debes revelar esas palabras a nadieindicó Lázaro. Cuando sientas que no puedes morir, haz lo que yo he hecho para poder hacerlo. Nunca las olvides. De lo contrario jamás podrás morir.

-¿Qué disparates son éstos, papá?

-¡Gracias, hija mía! ¡Gracias por permitirme morir en paz! Y perdóname por darte una carga tan pesada. ¡Gracias, gracias!

-¡Papá... me asustas!

La ventana estaba abierta. Una brisa suave hacía ondular las cortinas de la recámara. Isabel tiritó un poco.

-Él viene ya - dijo su padre con aire triunfante- Vete, hija mía, vete y déjame morir en paz.

Isabel contempló a su padre: en su rostro dibujaba una sonrisa de felicidad y triunfo. Isabel caminaba de espaladas a la puerta, siempre observando al moribundo. Abrió 
la puerta y la cerró suavemente, sin dejar de pensar en lo que su padre le había revelado. "Niño blanco, torre del norte, rosa negra, viento del suelo..." esas palabras le hacían pensar que su padre deliraba debido a la alta fiebre.

-Rosa negra...-repitió suavemente, sin darse cuenta de que la enfermera estaba sentada al lado de la puerta.

-¡Rosa negra!- repitió la enfermera, frunciendo el entrecejo- Tal cosa no existe, señorita Isabel.

-¡No me hagas caso, Alma! Solo pensaba en voz alta.

Isabel torció a la izquierda, tomando el pasillo que la llevaría al gran salón donde todos los hijos, nietos, nueras, cuñados, bisnietos y tataranietos de Lázaro aguardaban su llegada.

Ella caminaba con sus brazos cruzados, pensando, una y otra vez, en todas las cosas sin sentido que le dijo su padre

-¿Niño blanco?- preguntó Isabel, susurándose a sí misma.

-Él me contó lo que te lo dijo - oyó Isabel a sus espaldas.

Isabel se dio media vuelta. Sus ojos apreciaron a un niño blanco como la leche, desnudo, de cabello lacio y negro, de ojos completamente negros, su piel estaba adherida a sus huesos.

Isabel se sobresaltó y apoyó su cuerpo en una de las paredes. La respiración se le hizo pesada y las palpitaciones eran tan fuertes que sintió golpear con brutalidad su pecho.

-Él ya se fue, yo te haré compañía todas las noches por el resto de tu vida- dijo el niño.

A partir de esa noche y hasta su muerte, el niño blanco acompañó a Isabel. Le dio consejos de cómo usar las 13 palabras en su beneficio.

Años después, Isabel no podía morir. Isabel llamó a uno de los limosneros del pueblo, alegando ser su última voluntad.

Cuando el vagabundo salió de la habitación en la cual Isabel convalecía, estaba perplejo.

-¡Doña Isabel está loca! Delira con palabras sin sentido. Ha de ser por la fiebre que sufre - concluyó, con cierto desdén por lo revelado.

Aquel vagabundo se convertía en el loco del pueblo. 
